\title{
Análise da construção do conceito de Objeto Coreográfico através da triangulação metodológica: mutabilidade, transferibilidade
}

\author{
Analysis of the construction of the concept Choreographic Object through the \\ methodological triangulation: mutability, transferability \\ Análisis de la construcción de la noción de Objeto Coreográfico través de la \\ triangulación metodológica: mutabilidad, transferibilidad
}

\author{
Ana Medeiros ${ }^{1}$ \\ Zélia Teixeira ${ }^{2}$ \\ http://dx.doi.org/10.5216/32052
}

\section{Resumo}

O presente artigo tem como objetivo a apresentação de uma abordagem incomum no mundo das artes performativas. Partindo do conceito "objeto coreográfico" da autoria de William Forsythe (FORSYTHE, 2008) originalmente circunscrito à dança, pretendemos a clarificação e o aprofundamento quer do conceito em si, quer da sua aplicação em áreas como as artes performativas, práticas de produção e projeto de espaço. A presença de uma das autoras na equipa de produção de Scattered Crowd permitiu a conjugação de vários métodos de acesso aos atores principais desta peça: o próprio William Forsythe e dez elementos da equipa que construíram esta instalação. As entrevistas realizadas conjugaram-se com técnicas de exploração de significados e experiências como o recurso a objetos visuais e gráficos (cartaz) e a objetos-vídeo. A conjugação de quatro metodologias qualitativas diferentes constitui a sustentação do presente artigo. A conclusão da triangulação destas várias abordagens permite compreender o conceito de "objeto coreográfico" como um objeto de convergência. Esta ilação é derivada da investigação em curso. A convergência que o "objeto coreográfico" detém parece concretizar-se no efeito que requer e na forma como afeta quem o frequenta, o espetador.

Palavras-chave: Objeto coreográfico. Grounded analysis. Triangulação metodológica.

\begin{abstract}
The goal of this article is the presentation of an uncommon approach in the world of performing arts. Starting from the William Forsythe's concept of Choreographic Object (FORSYTHE, 2008), originally bound to dance, we aimed the clarification and exploration of both the concept itself and its application in areas such as the performing arts, production practices and the projection of space. Being integrated into the production crew of Scattered Crowd allowed the conjugation of methods of accessing the main performers of this play: William Forsythe himself and 10 elements of the crew who contributed to this installation. The interviews were conjugated with meaning and experience exploration techniques such as resorting to visual and graphic objects (poster) and video objects. The conjugation of the prospectives granted through four distinct qualitative methodologies constitutes the conclusion of this article. The completion of the triangulation of these various approaches allows you to understand the concept of "choreographic object" as an object of convergence. This conclusion is derived from the ongoing research. The convergence that "choreographic object" holds seems to materialize in the effect that requires and in the way it affects who attends it, the spectator.

\footnotetext{
${ }^{1}$ Doutoranda em Motricidade Humana, na especialidade de Dança na Universidade de Lisboa. Portugal, Lisboa. E-mail: ana.m.medeiros@gmail.com

${ }^{2}$ Psicóloga Clínica, Licenciada pela Universidade do Porto, Mestre em Psicologia da Educação e Doutorada em Psicologia pela Universidade do Minho. Professora Auxiliar na Faculdade de Ciências Humanas e Sociais da Universidade Fernando Pessoa (2004). Portugal, Cidade do Porto. E-mail: zelia@ufp.edu.pt
}

Comun. \& Inf., Goiânia, GO, v. 17, n. 2, p. 70-87, jul./dez. 2014 
Keywords: Choreographic Object. Grounded Analysis. Methodological Triangulation.

\section{Resumen}

El presente artículo tiene como objetivo la presentación de una propuesta inusual en el mundo de las artes a partir del concepto de "objeto coreográficas" escrito por William Forsythe (FORSYTHE, 2008) originalmente estaba limitado a la danza, queremos que la clarificación y la profundización del concepto en sí mismo y su aplicación en áreas tales como las artes escénicas, diseño práctico y la producción de espacio. La presencia de uno de los autores en equipo de producción dispersa multitud permitió la combinación de varios métodos de acceso a los principales actores de esta pieza: William Forsythe y diez miembros del equipo que ha construido esta instalación. Las entrevistas granate con las técnicas de exploración de significados y experiencias, como el uso de objetos visuales y gráficos (cartel) y los objetos de vídeo. La combinación de cuatro diferentes metodologías cualitativas es el soporte de este artículo. La conclusión de la triangulación de estos diversos enfoques nos permite comprender el concepto de "objeto coreográficas" como objeto de la convergencia. Esta lección se deriva de la investigación en curso. La convergencia en el sentido de que el "objeto" es coreográfico parece darse cuenta del efecto que requiere y cómo afectan a las personas que frecuenta el espetador.

Palabras clave: Objeto Coreográfico. Grounded analysis. Triangulación metodológica.

\section{INTRODUÇÃO}

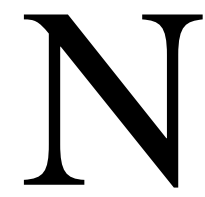

uma perspetiva pós-moderna, as artes performativas, aqui representadas pelo “objeto coreográfico" Scattered Crowd (instalação da autoria do coreógrafo William Forsythe) assumem um grande impacto no contexto sociocultural, beneficiando do cruzamento de várias áreas de conhecimento. Esta transdisciplinaridade surge na contemporaneidade, aqui são sentidas e questionadas as necessidades sobre a expansão do campo disciplinar da coreografia. A perspetiva de investigação que desenvolvemos reflete uma mudança de paradigma, uma valorização do processo e a emancipação do espetador no campo coreográfico. Através do "objeto coreográfico" Scattered Crowd (2013) esperamos perceber limites no processo, assim como encontrar balizas que configurem a contemporaneidade do conceito coreografia nas disciplinas de produção de espaço: campos da visualidade, da intencionalidade e do projeto. O domínio onde a coreografia está localizada, no "objeto coreográfico" e na instalação, são por definição áreas que não têm sido alvo de estudo científico, stricto sensu. Scattered Crowd (Figura 1) e aquilo que o contextualiza e lhe atribui circunstância de realização e produção é profundamente interessante. Verificámos isto através da nossa experiência, das diferentes particularidades e da propriedade genuína e autêntica encontrada nos documentos analisados de forma qualitativa. Tendo em consideração o referido, acreditamos existir a necessidade de adensar significados que têm sido vulgarmente utilizados tais como o conceito de instalação, "objeto coreográfico", coreografia etc. Optamos em relação a

Comun. \& Inf., Goiânia, GO, v. 17, n. 2, p. 70-87, jul./dez. 2014 
Scattered Crowd por explorar o conceito de "objeto coreográfico". Na versão realizada em 2013, de 20 a 24 de março, no Bockenheimer Depot em Frankfurt, estiveram presentes cerca de 2500 espetadores. A oportunidade de participar em Scattered Crowd e de pertencer à equipa de produção do objeto permitiu a clarificação de conceitos, tanto pela experiência de coprodução do objeto, como pela possibilidade em beneficiar da presença do coreógrafo William Forsythe (WF), reconhecido como um dos coreógrafos americanos contemporâneos mais importantes e cujo trabalho se distingue por reorientar a prática de ballet clássico para a arte dinâmica e participativa do século XXI. A sua obra releva da abstração e da teatralidade, desconstruindo o repertório do ballet clássico, incorporando assim, a palavra falada, a música experimental e os objetos coreográficos. O interesse de William Forsythe pelos princípios fundamentais e estruturantes da organização coreográfica levou-o a produzir uma ampla gama de projetos, incluindo instalações e filmes, assim como a criação de ferramentas pedagógicas para a produção de conhecimento na World Wide Web, tal como Synchronous Objects (2009).

No sentido de analisar o conceito de "objeto coreográfico" em Scattered Crowd recorremos ao ensaio do autor Choreographic Objects (Forsythe, 2008), como ponto de partida, perscrutando um conceito, uma noção imaterial e questionando a sua transposição no "objeto coreográfico" per se. Para tal procedemos à leitura do "objeto coreográfico" recorrendo a quatro instrumentos metodológicos qualitativos e complementares: entrevista semiestruturada a William Forsythe; cartaz 61 X85 cm Choreographic Objects (poster); entrevista semiestruturada a 10 elementos da equipa de produção do "objeto coreográfico" e o registo de experiências em vídeo destes 10 elementos entrevistados, confirmando-se o uso de abordagens qualitativas relevantes na análise da informação recolhida.

Figura 1 - Instalação Scattered Crowd (2013) no Bockenheimer Depot

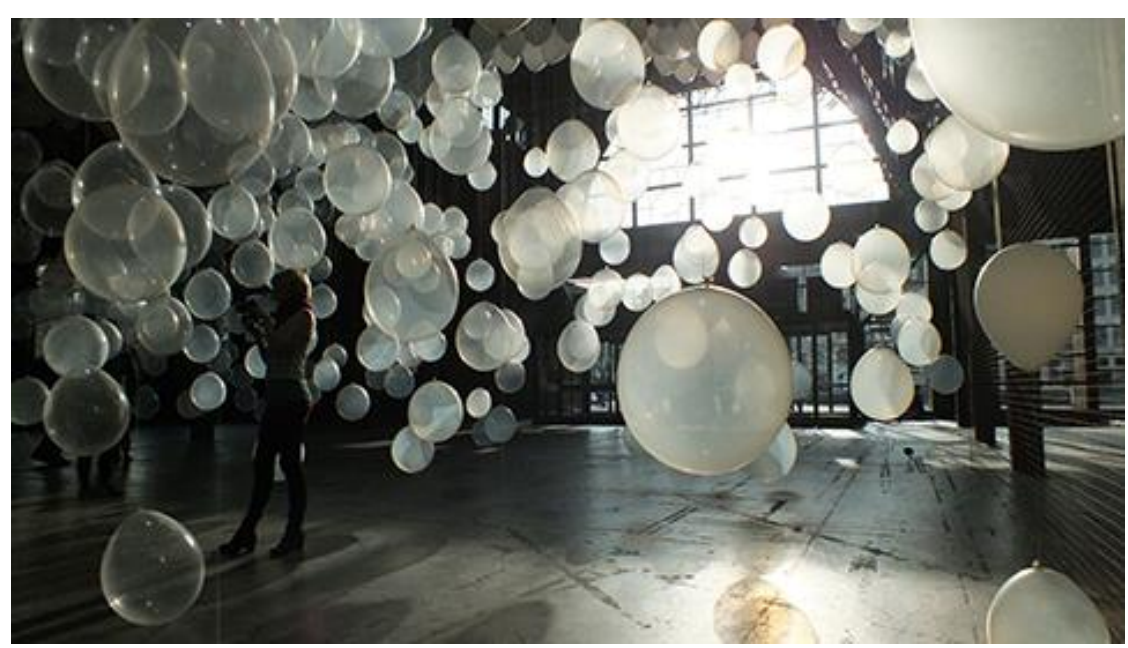

Comun. \& Inf., Goiânia, GO, v. 17, n. 2, p. 70-87, jul./dez. 2014 


\section{MÉTODO}

A escolha da metodologia qualitativa justifica-se pela pretensão de analisar a operacionalização do conceito "objeto coreográfico". Para tal elegemos a grounded theory (Teoria fundamentada nos dados) como método de análise de conteúdos discursivos para a nossa investigação, dada a subjetividade e amplitude de respostas com que nos deparámos. A grounded analysis (GA) consiste num conjunto de procedimentos qualitativos que visam contribuir para o desenvolvimento teórico do estudo em questão (Strauss \& Corbin, 2008). Esta prática permite organizar tecidos discursivos num exercício constante de descoberta, desenvolvimento e verificação provisória. A recolha de dados, a análise e a teoria estabelecem relações de reciprocidade e interligam-se. O processo de codificação na GA (Figura 2) constituiu-se por três fases fundamentais (Fonte, 2006) que passamos a descrever:

a) Codificação Aberta

Seleção do material relevante para análise: transcrição e leitura de cada entrevista, e na realização de uma síntese dos temas primordiais abordados; categorização descritiva: Categorização das unidades de análise, a partir do que é mais evidente ao longo de cada resposta; memoing: no processo de construção de categorias ocorrem ideias e hipóteses acerca do significado destas, das suas relações e ligações. Assim, através do memoing são construídos memorandos, permitindo uma melhor leitura e facilitando a abertura a insights.

b) Codificação Axial

Categorização conceptual: organização das categorias, que integram cada uma das categorias mais descritivas em categorias conceptuais, atingindo níveis mais abstratos.

c) Codificação Seletiva

Categorizações centrais: através do refinamento e das redes de relação construídas entre as categorias, surgem categorias centrais, que incluem as várias categorias conceptuais e são comuns às categorias conceptuais de cada entrevista; hierarquia de categorias: recorre-se de forma heurística à construção hierárquica, com base na categorização cumulativa e nas relações estabelecidas entre as diversas categorias conceptuais e categorias centrais em cada segmento discursivo; clarificação estrutural: através desta clarificação pretende-se mostrar a transparência da estrutura hierárquica do tecido discursivo emergente, pela integração ou suspensão temporária das categorias idiossincráticas, consideradas peculiares (usualmente consideradas unidades discursivas residuais), dado que apenas representam um ou dois sujeitos em todo o grupo.

Comun. \& Inf., Goiânia, GO, v. 17, n. 2, p. 70-87, jul./dez. 2014 
Figura 2 - Modelo teórico e fases na grounded analisys

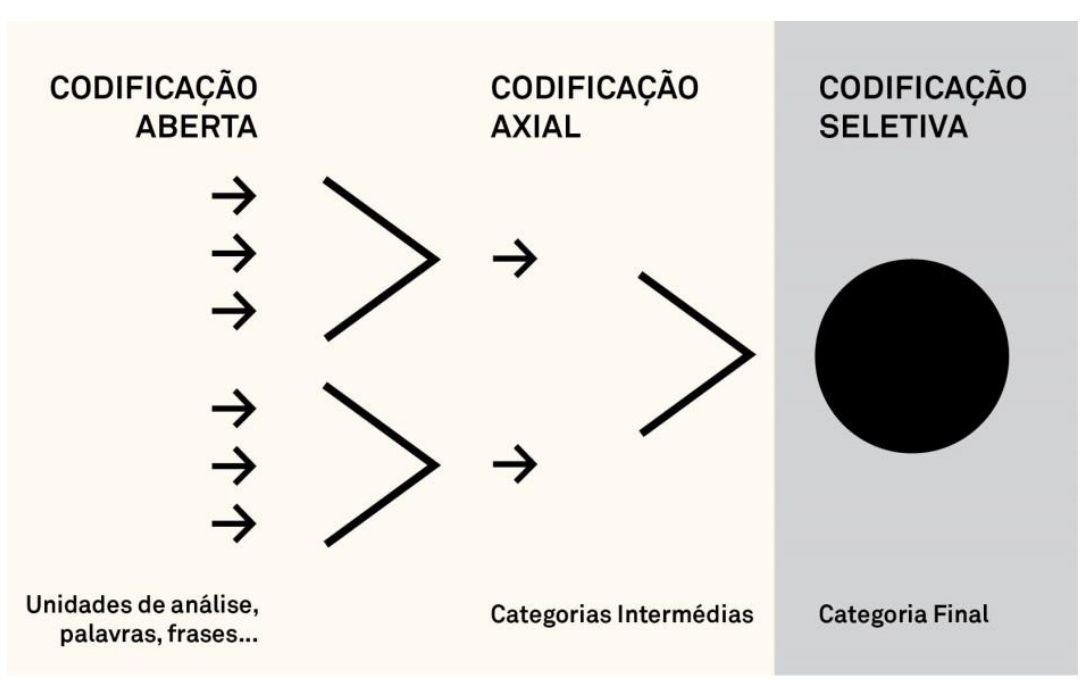

Terminada a descrição processual sumária da GA que nos permitiu trabalhar quer a entrevista a William Forsythe quer as dez entrevistas realizadas aos elementos da equipa de montagem de Scattered Crowd, importa referir que esta não foi a única forma de ler os fragmentos da realidade que a experiência nos proporcionou. $\mathrm{O}$ recurso a um conjunto de métodos interrelacionados possibilita a triangulação dos dados e métodos (Denzin, 1970). A triangulação lida nesta perspectiva pode assumir diversos contornos: a triangulação de dados refere-se à recolha da informação e recomenda o uso de diversas fontes neste processo; a triangulação de investigadores sugere a participação de diferentes investigadores no mesmo estudo possibilitando assim auferir múltiplas observações no campo assim como discussões de perspetivas, o que contribui para atenuar possíveis enviesamento; a triangulação de teoria refere-se à oportunidade do investigador recorrer a diversas teorias para esclarecer um conjunto de dados, e finalmente, a triangulação metodológica envolve a combinação de múltiplos métodos, geralmente o de observação e entrevista. Apesar de referenciada aqui, segundo Seale (1999), a interrelacionação entre a observação e a entrevista já tinha sido instituída por Becker e Geer em 1957. Optamos por uma triangulação metodológica dos instrumentos que apresentamos de seguida.

\subsection{Entrevista a William Forsythe}

A entrevista semiestruturada ao coreógrafo William Forsythe sustenta parte da reflexão teórica pretendida e serve de ponto de partida para as entrevistas com a equipa. Das treze questões elaboradas foram respondidas onze de uma forma direta e duas de forma indireta (resultando numa construção fragmentária da resposta ao longo da entrevista). Após a transcrição da entrevista, realizámos uma categorização descritiva das

Comun. \& Inf., Goiânia, GO, v. 17, n. 2, p. 70-87, jul./dez. 2014 
unidades discursivas, encontrando um significado nas suas vertentes decompostas, o que se revelou muito útil para a compreensão de algumas características e associações ligadas ao “objeto coreográfico". A entrevista sustentava-se na investigação do significado do termo coreografia, assim como na clarificação do conceito objeto coreográfico. A entrevista teve a duração de 1 hora e 31 minutos. Tendo em linha de conta a versatilidade e a dispersão do discurso do coreógrafo a análise que apresentamos foi alvo de três níveis distintos de reflexão: um nível de análise e interpretação direta aplicável a dez das questões do guião original (questões 1, 5, 6, 7, 8, 9, 10,11,12,13), outro indireto, sugerido pelas diversas intervenções no suporte cartaz e pelo mapeamento das intervenções no mesmo (questão 3) e recorremos ainda um outro nível distinto e mais profundo, aplicado às questões 2 e 4, que pressupôs uma desconstrução de conceitos, uma procura de significados subjacentes à fluidez do discurso do autor, indispensáveis à clarificação dos conceitos anteriormente referidos: coreografia e "objeto coreográfico". A GA permitiu a construção de uma grelha de clarificação que aplicamos ao discurso emergente das resposta às questões 2 e 4. A título de exemplo colocamos a Tabela 1 que corresponde à questão 2 do guião. No entanto iremos analisar a questão 4 no presente artigo por ser aquela que corresponde à caracterização mais aprofundada do conceito "objeto coreográfico".

\subsection{Cartaz 61X85 cm Choreographic Objects}

O cartaz pode ser considerado uma extensão, uma sustentação e um alargamento do instrumento anterior - a entrevista a William Forsythe. No design do cartaz, o texto (ensaio Choreographic Objects), que inicialmente tinha doze parágrafos, colocado na página, de forma intencional, existindo uma apresentação e espaço para a escrita no próprio cartaz, com duas configurações distintas: a do registo já impresso e escrito e a do registo ainda por inscrever. O espaço que sobrava na página estava desenhado e restringido de forma a existir como lugar de intervenção. Através desta descrição gostaríamos de esclarecer que o texto não ocupou todo o espaço do papel. A partir deste objeto/instrumento pretendíamos que WF tivesse condições para sustentar uma reflexão sobre o ensaio plasmado, cinco anos após a sua escrita e perceber o que este teria a acrescentar desde a publicação deste trabalho.

Comun. \& Inf., Goiânia, GO, v. 17, n. 2, p. 70-87, jul./dez. 2014 


\subsection{Entrevista a 10 elementos da equipa de produção}

As entrevistas individuais realizadas a dez membros da equipa da produção de Scattered Crowd (50\% do total da equipa) tiveram lugar no espaço da instalação, entre os dias 23 e 24 de março de 2013. As entrevistas foram registadas em áudio, com o consentimento informado de cada um dos participantes. Os sujeitos pertencem a uma faixa etária entre os 22 e 33 anos, são do sexo feminino e encontram-se a residir na Alemanha, apesar de nacionalidades diversas. A entrevista individual teve como objetivo a recolha de discursos e de experiências sobre o "objeto coreográfico" em construção. Através da entrevista pretendemos fazer emergir proposições e conceitos produzidos pelo próprio grupo, sobre a operacionalização do conceito "objeto coreográfico", e sobre a produção e co-construção de Scattered Crowd. O guião da entrevista semiestruturada tinha seis questões que abrangiam temáticas que iam desde a caracterização do "objeto coreográfico" até à liberdade do espetador, e foi construído tendo em conta a necessidade de recolher a experiência e o conhecimento dos elementos da equipa de construção do "objeto coreográfico", enquanto interlocutores privilegiados, dadas as suas funções na instalação Scattered Crowd. As entrevistas tiveram uma duração entre os 8,43 minutos e os 29,19 minutos, e o seu conteúdo foi analisado com base na a entrevista ao autor da instalação.

\subsection{Experiência: vídeo dos 10 elementos da equipa}

$\mathrm{O}$ instrumento de recolha de informação que sustentou este registo sob a forma de objeto-vídeo foi a câmara. Uma câmara era disponibilizada antes de cada entrevista a cada elemento da equipa, de modo a que, de acordo com a sua motivação, a sua intenção e background, fosse possível captar a visão/envolvimento de cada sujeito, registando a sua experiência e interação. O resultado advém de fatores tão pessoais como a escolha do local do corpo onde a câmara era posicionada, ou o percurso escolhido para se relacionar com a instalação Scattered Crowd (2013). Podemos constatar que as experiências têm uma duração mínima de 1,51 minutos e máxima de 38,52 minutos. A análise da informação recolhida foi sistematizada consoante o fator tempo e através de diagramas espaciais, e é essencialmente descritiva, tornando mais clara a sua legibilidade como processo em construção. A metodologia adotada situa-se na fronteira ente o vídeo experimental e a análise documental. 


\section{DESCRIÇÃO DOS RESULTADOS OBTIDOS}

O campo artístico é detentor de múltiplas e complementares linguagens. Assim o termo coreografia sustenta e legitima práticas artísticas contemporâneas e, nesse sentido, a concepção das instalações choreographic objects, podem ser referidas como exemplo. Todo o processo de recolha de informação sustentada nos instrumentos acima referidos decorreu no enquadramento de uma metodologia de investigação ativa e de observação participante. Teve lugar na cidade de Frankfurt entre os dias 20 e 24 do mês de Março de 2013. Os critérios de selecção dos elementos entrevistados foram: disponibilidade, vontade e envolvimento no processo de produção do objeto. As entrevistas foram registadas em áudio, com o consentimento informado de cada um dos participantes. Cada participante sentou-se de frente para a instalação, com a visualização permanente do "objeto coreográfico" durante o período em que estava aberto ao público. Devido à barreira linguística, decidimos entregar uma folha com a sequência de perguntas a cada entrevistado. Nessa folha estavam as questões que iríamos colocar, exceptuando as questões que faziam parte do processo de integração com o interlocutor. Sendo assim, os sujeitos, depois de responderem a questões pessoais, tais como, nome, nacionalidade, intenções, estavam aptos e disponíveis para responder às nossas perguntas. No que concerne à experiência individual de cada elemento da equipa, foi proposto aos participantes (aos mesmos que responderam à entrevista) que escolhessem uma parte do corpo para posicionar uma câmara e foi pedido que experienciassem o objeto coreográfico, que mostras- sem a forma como compreendiam o espaço. Ao mesmo tempo que os sujeitos experienciavam o espaço, o registo sob a forma de diagram estava a ser realizado por nós, com o objectivo de não perdermos toda a dimensão processual na qual a equipa estava envolvida, conforme explanado na Figura 4. Não cabe no formato do presente artigo a partilha aprofundada dos conteúdos emergentes das quatro formas de recolha de informação por nós selecionadas. No entanto, apresentaremos exemplos do processo de análise dos dados obtidos, como clarificadores das metodologias aplicadas.

\subsection{Análise qualitativa da entrevista a William Forsythe}

Das 13 questões contempladas no guião descreveremos sucintamente os conteúdos suscitados em duas delas, por relevarem temáticas centrais para o propósito do presente estudo: clarificar o conceito de "objeto coreográfico" e, consequentemente explanar a

Comun. \& Inf., Goiânia, GO, v. 17, n. 2, p. 70-87, jul./dez. 2014 
abrangência da noção adjacente de coreografia. Como resultados obtidos com a questão In your opinion, what characterizes a Choreographic Object? alcançámos depois da análise das unidades discursivas individuais, da sua categorização em entidade de significado intermédias, e finalmente da organização destas últimas em núcleos agregadores de significados finais, treze categorias emergentes do tecido discursivo de WF. Temos pois o "objeto coreográfico" como: Gerador de mudanças nos vários domínios do indivíduo (comportamental e emocional); objeto com dimensão inconsciente; sistema complexo e volátil; sustenta-se em regras e condições; sustenta-se no envolvimento; regra de substituição de significados; processo de mudança individual; mutável; com um propósito (múltiplas funções); sustentado num contexto; objeto com dimensão consciente; uma equação e sustentado em referências. Os treze núcleos de significado finais são esclarecedores, mas as categorias intermédias (CI) que lhe deram origem fazem sobressair particularidades que nos permitem ter uma compreensão mais exata e profunda sobre o que caracteriza, para William Forsythe, um "objeto coreográfico". Apenas como exemplo do processo realizado, e quanddo nos centramos no núcleo de significado emergente, gerador de mudanças nos vários domínios do indivíduo (comportamental e emocional) (com 26 referências no discurso), este é sustentado em três CI: Gerador de mudança no comportamento (10 Ref.), gerador de comportamentos (7 Ref.), e provocador de emoções (9 Ref.). Já a questão 2 "While reading Choreographic Objects, the following question crossed my mind: what range does the notion of choreography have for you?" resultou numa menor profusão de categorias, e a Tabela 1 apresenta a globalidade do processo de categorização realizado (Tabela 1). A grounded analysis revela-nos que os núcleos de significado mais relevantes (categorias finais) e respostas à questão definem a amplitude da noção de coreografia recorrendo a cinco vetores conceptuais: Estrutura organizada e intencional; com dimensão temporal e dinâmica; disciplina de integração; sustentada numa máquina semântica e assente no movimento. A questão 2 foi fundamental nesta investigação. O criador levou-nos a sistematizar o seu discurso, a realidade observada e a encontrar respostas à questão colocada, percorrendo caminhos alternativos.

Tabela 1 - Categorias intermédias e finais obtidas na questão 2

\begin{tabular}{|c|c|c|}
\hline \multicolumn{1}{|c|}{$\begin{array}{c}\text { Unidades Discursivas } \\
\text { (excertos da entrevista - codif. aberta) }\end{array}$} & $\begin{array}{c}\text { Categorias } \\
\text { intermédias } \\
\text { (codif. axial) }\end{array}$ & $\begin{array}{c}\text { Categorias } \\
\text { finais } \\
\text { (codif.seletiva) }\end{array}$ \\
\hline $\begin{array}{l}\text { "Medium of dancers to accomplish its means". } \\
\text { "Choreograph yourself with your own engagement, with } \\
\text { politics into a state of inactivity". }\end{array}$ & $\begin{array}{c}\text { Intencionalidade } \\
\text { (7 Ref.) }\end{array}$ & $\begin{array}{c}\text { Estrutura } \\
\text { organizada e } \\
\text { intencional }\end{array}$ \\
\hline
\end{tabular}

Comun. \& Inf., Goiânia, GO, v. 17, n. 2, p. 70-87, jul./dez. 2014 


\begin{tabular}{|c|c|c|}
\hline $\begin{array}{l}\text { "You manage to disable". } \\
\text { "Choreography implies will ..." } \\
\text { "Used to get rid of the idea of chance". } \\
\text { "Disengage yourself". } \\
\text { "Implies intent". }\end{array}$ & & \multirow[t]{3}{*}{ (13 Ref.) } \\
\hline $\begin{array}{l}\text { "Set of parameters in terms of skill". } \\
\text { "Very different set of conditions". } \\
\text { "So the word is used in all kinds of situations that imply a } \\
\text { certain level sophisticated organization or intentional } \\
\text { organization". }\end{array}$ & $\begin{array}{l}\text { Parâmetros } \\
\text { (3 Ref.) }\end{array}$ & \\
\hline $\begin{array}{l}\text { "Fixed audience" } \\
\text { "The skill of the construction of the performance". } \\
\text { "Distance of the audience". }\end{array}$ & $\begin{array}{l}\text { Organizačão } \\
\text { configuradora } \\
\text { (3 Ref.) }\end{array}$ & \\
\hline $\begin{array}{l}\text { "Ephemerality thing that what makes choreography } \\
\text { valuable". } \\
\text { "Narrower..." }\end{array}$ & $\begin{array}{l}\text { Narrativa } \\
\text { (2 Ref.) }\end{array}$ & \multirow{2}{*}{$\begin{array}{l}\text { Com } \\
\text { dimensão } \\
\text { temporal } \\
\text { e dinâmica } \\
\text { (4 Ref.) }\end{array}$} \\
\hline $\begin{array}{l}\text { "A real stage choreography doesn't use every single } \\
\text { dynamic that's available to human beings". } \\
\text { "You can't include the entire category of all human } \\
\text { dynamic and timed interaction". }\end{array}$ & $\begin{array}{l}\text { Dinâmica } \\
\text { Temporal } \\
\text { (2 Ref.) }\end{array}$ & \\
\hline $\begin{array}{l}\text { "Choreography, as I say in the essay, and dance are two } \\
\text { different disciplines". } \\
\text { "They can be linked but they don't have to be linked". } \\
\text { "It could only include certain sets categories". }\end{array}$ & $\begin{array}{l}\text { Disciplina } \\
\text { de integração } \\
\text { (3 Ref.) }\end{array}$ & $\begin{array}{l}\text { Disciplina } \\
\text { de integração } \\
\text { (3 Ref.) }\end{array}$ \\
\hline $\begin{array}{l}\text { "This is a language machine and one cannot find another } \\
\text { or better therefore this name and object you can replace" } \\
\text { "The word choreography is not so possessed by its own } \\
\text { previous definitions that one could not find another or } \\
\text { better therefore". }\end{array}$ & $\begin{array}{l}\text { Sustentada } \\
\text { numa } \\
\text { máquina } \\
\text { semântica } \\
\text { (2 Ref.) }\end{array}$ & $\begin{array}{l}\text { Sustentada } \\
\text { numa } \\
\text { máquina } \\
\text { semântica } \\
\text { (2 Ref.) }\end{array}$ \\
\hline $\begin{array}{l}\text { "It uses some movements". } \\
\text { "Some sets of coordination, motion, position duration...". }\end{array}$ & $\begin{array}{l}\text { Assente no } \\
\text { movimento } \\
\text { (2 Ref.) }\end{array}$ & $\begin{array}{l}\text { Assente no } \\
\text { movimento } \\
\text { (2 Ref.) }\end{array}$ \\
\hline
\end{tabular}

\subsection{Análise do cartaz $61 \times 85 \mathrm{~cm}$ Choreographic Objects}

Pretendíamos com o cartaz perceber o que William Forsythe mudaria no ensaio que escreveu em 2008, e entender que relação William Forsythe poderia estabelecer com o suporte visual e gráfico, objeto puramente textual. A valorização do cartaz emerge da relação dialógica entre o artista e o objeto, e está patente no movimento que antecede a inscrição, a fixação, e o sublinhar de ideias importantes para o artista visual, mostrando a afiliação do autor com a nossa estratégia. O cartaz permitiu produção de conhecimento, pois a presença física e interpeladora da investigadora faziam WF voltar ao objeto "cartaz", e esclarecer o que não tinha sido determinado em qualquer momento da entrevista. William

Comun. \& Inf., Goiânia, GO, v. 17, n. 2, p. 70-87, jul./dez. 2014 
Forsythe realizou mudanças nas opções que tinha tomado para a composição do ensaio, problematizou constantemente a primeira proposição do documento que é da autoria de René Magritte: “An object is not so possessed by its own name that one could not find another or better therefore" (Gablik, 1970). Na Figura 3 mostramos o mapeamento das intervenções do coreógrafo no suporte que contou com 42 entradas (palavras) de William Forsythe, entendidas como valorizações e acrescentos ao pensamento anteriormente desenvolvido (Figura 3). Sumariamente expomos as primeiras entradas: Aos 15,05 minutos de entrevista, WF risca da frase de Magritte a palavra name (entrada 1) e acrescenta function; context; history of usage e etc (An object is not so possessed by its own name that one could not find another or better therefore), seguindo-se a palavra object. Continuando, WF escreve e sublinha a palavra practice (entrada 5), desta vez lendo o que escreveu " $A$ practice is not so possessed by its own history of process (acrescenta esta nova definição) that one could not find another or better therefore". WF explica que esta frase de é claramente uma máquina semântica, onde a palavra name e object podem ser substituídas e envolver outros parâmetros, que, segundo WF, permitem uma categorical analisys (entrada 7). $\mathrm{O}$ autor restringe a palavra object e a palavra name, e de uma forma gestual e reflexiva, escreve What else? - Explica a sua questão mencionando que esta é uma oportunidade de sermos criativos. Forsythe continua e escreve Would be adequate to allow this "equation" to function? (entrada 10). Ao refletir sobre a frase anterior e ao verbalizar novamente a equação formulada por Magritte, aos 18,44 minutos, escreve mobility (entrada 11) dizendo que este é o grande momento, pois a mobilidade explica que até mesmo os objetos não permanecem nos seus lugares, nem que seja através de outros patamares de significação. Ao refletir sobre a frase anterior e ao verbalizar novamente a equação formulada por René Magritte, aos 18,44 minutos, Forsythe escreve "mobility" (entrada 11) dizendo que este é o grande momento, pois a mobilidade explica que até mesmo os objetos não permanecem nos seus lugares, nem que seja através da atribuição de outros significados. Uma postura mais gestual perante o suporte cartaz é assumida na entrada seguinte, talvez pelo que as palavras significam e evocam para o autor: palco, espaço de palco, fora do palco, em palco. Forsythe risca novamente a palavra "object" da frase de Magritte e escreve no cartaz "off stage" (entrada 12), e elucida que qualquer outra coisa está “on stage" (entrada 13), ou seja está a funcionar e em perfeita equação. Ao fazer uma pequena referência à palavra objeto, o autor imediatamente escreve e enfatiza a palavra “incompatibility" (entrada 14). Recorre a este adjetivo para separar "Choreographic" e

Comun. \& Inf., Goiânia, GO, v. 17, n. 2, p. 70-87, jul./dez. 2014 
"Objects" (título do ensaio). Explicamos esta postura: "Magritte never dealt with single, static identities. His images incorporate a dialectical process, based on paradox, which corresponds to the unstable, and therefore indefinable, nature of universe" (GABLIK, 1970, p.108).

Figura 3 - Excerto do cartaz 61X85 cm Choreographic Objects

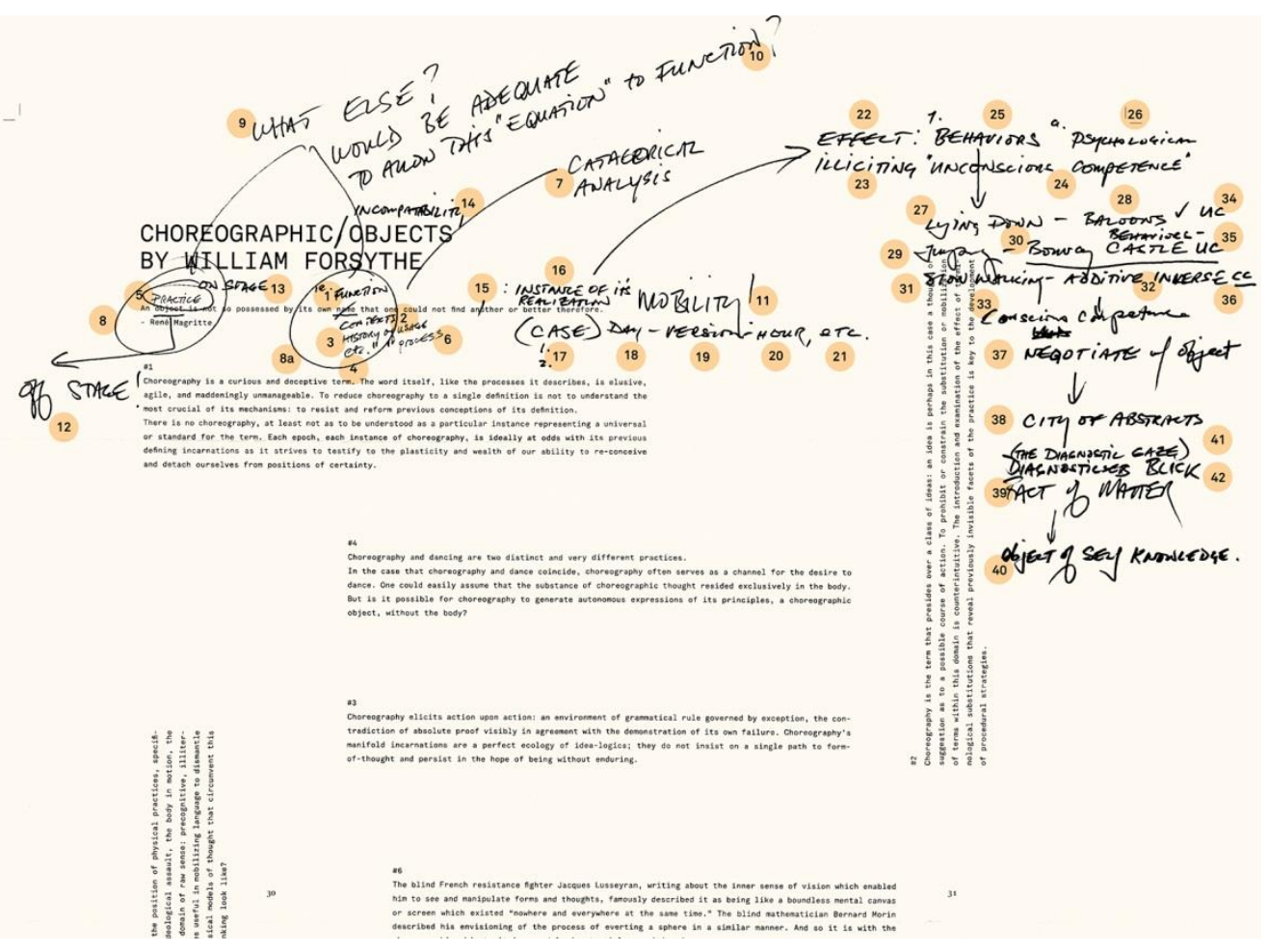

\subsection{Análise qualitativa da entrevista a 10 elementos da equipa de produção}

Das 6 questões contempladas no guião descrevemos sumariamente os conteúdos suscitados na que pretendia clarificar o conceito de "objeto coreográfico" - In your opinion, what characterizes a Choreographic Object?. Depois da análise das unidades discursivas individuais e consequentemente da sua categorização surgiram como núcleos agregadores de significados finais 8 categorias. Para a equipa o "objeto coreográfico" tem como características: o envolvimento; a dimensão espacial; o movimento; a configuração; a dança; a transformação; o desdobramento e a performance. Podemos constatar que sete sujeitos não tinham resposta para a pergunta formulada. Os conceitos acima enunciados emergem do tecido discursivo dos dez entrevistados e aparentemente são complementares aos enunciados por WF. Como exemplo da dimensão Envolvimento (N=6; 14 Referências) encontramos quatro CI (contacto, interação entre sujeitos e espaço; interação entre sujeito e coreografia; fusão do objeto com o sujeito).

Comun. \& Inf., Goiânia, GO, v. 17, n. 2, p. 70-87, jul./dez. 2014 


\subsection{Análise da experiência vídeo dos 10 elementos da equipa}

Foi solicitado a cada elemento que documentasse a sua experiência no "objeto coreográfico" Scattered Crowd, antes da entrevista. A decisão de analisar as experiências de cada entrevistado e de as tornar instrumentos de leitura de Scattered Crowd, revelou-se complexa dado os pontos que seguidamente apresentaremos. Para uma possível atualização das nossas dúvidas sobre os objetos-vídeo obtidos em Março de 2013, iremos compará-los, clarificar ligações e explicações que se apresentam como desafios. A análise dos percursos de cada sujeito foi realizada a partir da combinação da gestão temporal e do diagrama espacial. Todas as anotações à experiência que estão relacionadas com o fator tempo e percurso foram factuais. As anotações que mostram suposições ou criam hipóteses, tais como, "processo documental”, "espanto”, são propostas subjetivas consideradas por nós.

Em tom de nota exemplificamos a produção de um sujeito na instalação. O sujeito 3 e o sujeito 5 (Figura 4) escolheram a zona da anca, mais especificamente a zona ilíaca, para colocar o dispositivo vídeo. Na análise do objeto-vídeo do sujeito 3 podemos notar que colocou o dispositivo na zona ilíaca direita. Escolheu a entrada 1 e demorou cerca de 3,12' minutos a documentar a sua experiência. Durante todo o seu percurso, essencialmente do lado esquerdo da instalação, compôs os balões pelo espaço, numa possível reminiscência da sua prática diária, enquanto membro da equipa de produção. $\mathrm{O}$ ritmo da passada era acelerado, quase de corrida, que podemos observar através do movimento acelerado dos braços que surge continuamente no filme. Para além da aceleração, o sujeito desvia-se dos outros espetadores, não observando ninguém. Um percurso quase em linha reta, como ficou registado no diagrama que desenhamos.

Da análise do vídeo do sujeito 5, podemos notar que elegeu a zona ilíaca esquerda, para colocar o dispositivo de gravação e documentação. Demorou cerca de 23,52' minutos a realizar a experiência. $\mathrm{O}$ sujeito 5 foi o sujeito que demorou mais tempo a percorrer e a documentar a sua experiência na instalação. Optou por um percurso sinuoso, partindo da entrada 2 com alguma indecisão. Ao minuto 1,15' pega num balão, contempla-o e procura espaços vazios. Ao longo do seu percurso pára várias vezes, observa comportamentos, crianças a brincar, detém-se por momentos a contemplar. De acordo com o diagrama, podemos verificar que optou por mapear quase todo o espaço, percorrendo-o. O sujeito 3 e o sujeito 5 apesar de terem escolhido a mesma zona corporal para a colocação da câmara, obtiveram objetos-vídeo distintos. Os objetos apenas se cruzam nos já referidos desembaraçar de fios e composição de balões no espaço da instalação, vislumbres ou

Comun. \& Inf., Goiânia, GO, v. 17, n. 2, p. 70-87, jul./dez. 2014 
vestígios da sua prática diária.

Figura 4 - Diagrama espacial dos sujeitos 3 e 5, respetivamente.
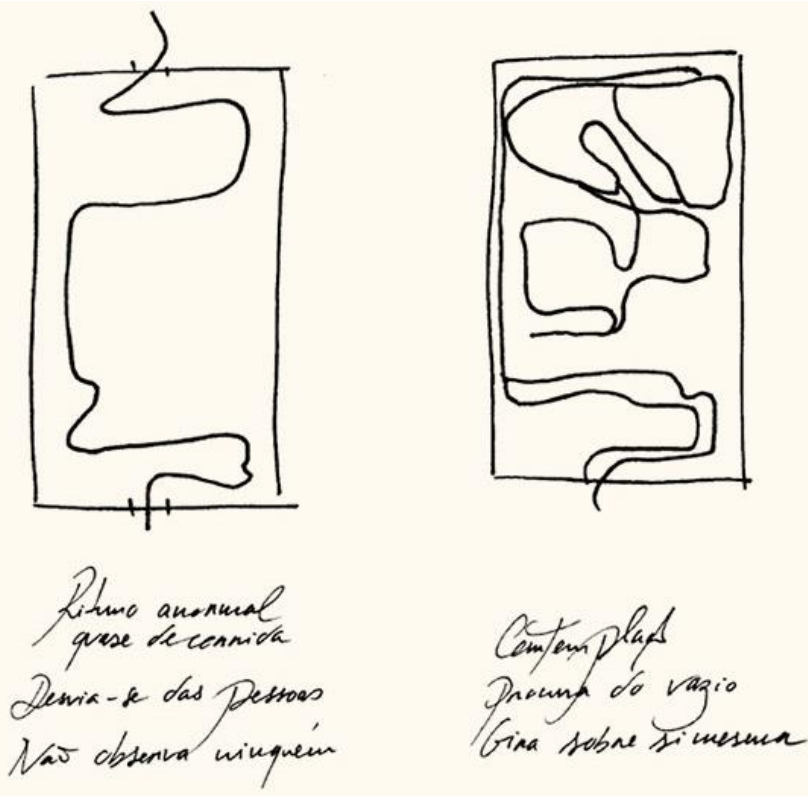

\section{CONVERGÊNCIA DE METODOLOGIAS}

A partir de vários instrumentos metodológicos recolhemos respostas a propósito dos objetivos que definimos no sentido de esclarecer o conceito "objeto coreográfico" e confirmamos as vantagens em recorrer a diversas abordagens. Desta interação construímos a nossa grelha complementar do discurso de William Forsythe, que se apresenta como um aporte de conhecimentos que os instrumentos metodológicos nos permitiram produzir.

Situamos pois o "objeto coreográfico" nas recentes práticas de produção e projeto de espaço, na medida em que abre possibilidades relacionais ao espetador, transportando-o para uma esfera ativa de receção, coprodução contextual e interpretação. A nossa experiência em Scattered Crowd faz-nos pensar que a coreografia poderá residir em elementos diversos, e que a contemporaneidade experimenta através dos objetos coreográficos de WF noções de coprodução e presença. Noções dialógicas, onde convergências e divergências relacionais entre sujeito, objeto e significado são os ingredientes para o acontecer dos "objetos coreográficos". Para o coreógrafo, o que caracteriza o "objeto coreográfico" (OC) é o facto de estar imbuído de um ponto de vista estrutural, e por isso se assemelhar a uma partitura. Para o criador, o OC apresenta duas dimensões: a dimensão consciente e a inconsciente. Sustenta-se através de regras e realizase no envolvimento, concretamente no compromisso de negociação entre o objeto e o sujeito. É um elemento transformador, provocador, sobretudo gerador de mudanças

Comun. \& Inf., Goiânia, GO, v. 17, n. 2, p. 70-87, jul./dez. 2014 


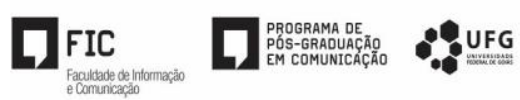

comportamentais e emocionais no sujeito. Acrescentamos que provoca inconscientemente mudanças no sujeito e consequentemente no espaço, sendo a intencionalidade uma possibilidade de projeto coreográfico. Reúne condições para que cada interveniente possa construir uma relação. Na entrevista, Forsythe referencia o processo de mudança individual (self), e à promoção do autoconhecimento, como sendo particularidades do "objeto coreográfico". Falamos de um self saturado, multifacetado e dinâmico. O OC permite a criação de narrativas pessoais e gera qualidades como a de autoconhecimento e a de alerta. Nós, sujeitos comuns, teremos que, "de forma inconsciente", encontrar formas/fórmulas de superação do contexto criado pelo objeto. Esta máquina semântica, nós diríamos de tradução, que é o OC explica-se através de uma proposição de Magritte e nessa condição o OC gera espanto, excentricidade, disparidade e deixa a compreensão sobre o que está diante de nós ao arbítrio, universo e realidade de cada um. William Forsythe no cartaz, problematiza esta máquina semântica continuamente, quando completa e acrescenta significados. Percebemos que a relação que o objeto visual e gráfico propõe, é uma relação instantânea - tudo o que foi escrito e sentido não tem um valor absoluto, tem o valor do momento, um valor sequencial associado a uma narrativa discursiva (anteriormente acedida através da grounded analysis). Forsythe, à medida que ia escrevendo, lia em voz alta, parecendo que por vezes procurava um fio condutor no seu discurso, sublinhando e criando conceitos que naquele momento pareciam fazer sentido.

Podemos depreender que o suporte visual o ajudou a pensar, tornou-se uma ferramenta. Todas as anotações realizadas facilitaram o diálogo que estabeleceu com o texto em si, projetando desta forma uma nova narrativa, um diálogo, que existiu instantaneamente ligado a um espaço-tempo. Encontramos pontos de convergência na entrevista à equipa na medida em que também ela admite que o objeto é gerador de mudança e só assim permite o envolvimento. Neste grupo existiram temáticas transversais, tais como a dimensão espacial, a dimensão do movimento e a dimensão do envolvimento. Este último, tantas vezes sugerido por WF, realiza-se através de uma experiência de contacto cumulativa, dilatada e democrática com o OC. O objeto precisa de regras performativas, da configuração dimensional e da abertura e disponibilidade do espetador para o espaço de negociação que se traduz no envolvimento, pois ao ser considerado um sistema comunicante e volátil, uma pequena sociedade construída momentaneamente e de forma quase instintiva está permanentemente em mutação. Nesta sociedade referida, existe o criador, a equipa de produção e o espetador. Estes dois últimos podem contribuir e

Comun. \& Inf., Goiânia, GO, v. 17, n. 2, p. 70-87, jul./dez. 2014 


\section{口㚏 口}

usufruir do $\mathrm{OC}$ sem terem presente ou dissecado o conceito em questão. Não será necessário perceber e interiorizar o conceito, para estar dentro e envolvido no objeto. $\mathrm{O}$ que se revela essencial é a diferente mediação que cada interlocutor faz e permite. Cada elemento da equipa é um mediador na construção do resultado em atualização, de um corpo-em-projeto. O OC elege o corpo como elemento mediador de trocas entre sujeito e objeto. Sem corpo não existe contacto, a coreografia é um instrumento, e no OC, mantém o mesmo estatuto e função. O corpo é o instrumento mais importante, pois é através dele que o espaço e o objeto são afetados. O OC é um ponto de partida para transições e estados evolutivos entre o sujeito e o objeto, tem uma mensagem, e apresenta-se de forma inacabada. Para além disto é uma possibilidade fenomenológica: "A choreographic object, or score, is by nature open to a full palette of phenomenological instigations" (Medeiros, 2014). Apresenta-se como uma palete repleta de desafios, relacionando o potencial que cada sujeito tem de construção de uma realidade própria, em articulação com o objeto naquele espaço-tempo. O OC permite o autoconhecimento, talvez por isso também desencadeie a aprendizagem dos fenómenos em profundidade, e encerra em si uma condição de possibilidade. As referências de outros autores são importantes para WF no que concerne à execução e reflexão sobre as características de um OC. Forsythe alude a Olafur Eliasson e refere dimensão do envolvimento como sendo a que está mais presente num “objeto coreográfico". Esta dimensão criada por Eliasson permite perceber as vantagens das novas formas de expressão artística que requerem o envolvimento, abordagens que refletem uma forma diferente da relação do humano com a arte na contemporaneidade, percebendo-se desta forma que é uma arte onde não existe distância.

$\mathrm{Na}$ equipa, conseguimos perceber através dos vídeos que a atitude contemplativa foi a que predominou, atribuindo e sugerindo muitas vezes ao sujeito o papel de voyeur. $\mathrm{O}$ questionar ficou contido na contemplação, na atitude de descoberta e no voyeurismo, no desvinculamento da experiência, pelo que pudemos constatar da análise realizada. Cruzando a análise das experiências vídeo da equipa com a questão 4 da entrevista, verificamos que os vetores com maior peso e referentes ao comportamento esperado dos espetadores na instalação são a disponibilidade para a experiência e a interação. Sendo que a entrevista foi realizada antes da experiência vídeo, revela-se um pouco contraditório aquilo que os sujeitos esperavam e aquilo que realmente aconteceu nos objetos-vídeo pessoais. Não querendo isto dizer que o grupo não fez uma tentativa de imersão. Talvez o facto da equipa ter sido confrontada sempre com o objeto em processo, e nunca com o 
"objeto coreográfico" final, não tenha facilitado realizar a retenção e captação da experiência de envolvimento através dos conceitos sugeridos pelos entrevistados: disponibilidade para a experiência e interação. Provavelmente, o discurso da equipa reflete apenas o impacto do processo, mais do que o impacto do resultado.

\section{CONCLUSÕES}

Um dos objetivos da arte contemporânea parece ser a de que os indivíduos encontrem o seu próprio sentido na obra, procurando desta forma o envolvimento. Apesar deste ser inequivocamente uma das características primordiais do "objeto coreográfico" ao fazermos uma leitura dos objetos-vídeo parece existir um desvinculamento quase completo por parte da equipa na sua experiência. Podemos atribuir esta ausência de envolvimento, ao facto do grupo ser confrontado continuamente com o objeto em processo. A repetição sem fim, cíclica do projeto em processo está assente numa metodologia coletiva de trabalho ausente de questões e espanto, talvez porque a equipa tenha sido confrontada com o objeto em processo e nunca com o objeto final. Quanto aos espetadores, consideramos serem grande parte do evento na medida em que são eles que interagem, decidem e podem fazer alterações com maior visibilidade.

Sendo o "objeto coreográfico" Scattered Crowd, o exemplo analisado exaustivamente, ele constitui, na nossa perspetiva, um dispositivo peculiar e com características próprias. A coreografia que é pensada para o “objeto coreográfico” poderá ter características mutáveis, passíveis de nova significação, acentuando a capacidade de transversalidade e transferibilidade entre objetos artísticos. Ao optarmos na análise por realizar uma triangulação metodológica pretendíamos obter maior clareza na análise da informação. Pensamos ter conseguido atingir os objetivos. $\mathrm{O}$ valorizar da subjetividade fez com que optássemos por um conjunto de análises e de procedimentos qualitativos. $\mathrm{O}$ recurso a um conjunto de métodos interrelacionados possibilita a triangulação dos dados e métodos, facilitando a emergência de áreas de intersecção e cruzamento conceptuais, que não convergiriam se não proviessem de atores diversos. A inovação nos instrumentos de análise mostra-nos uma abertura quer no "objeto coreográfico", que nunca é um produto final, quer no desenho da investigação, que se conforma e configura mediante oportunidades privilegiadas como foi a participação em Scattered Crowd (2013): uma abordagem experimental num campo de especialização rígidos e hierarquizado tal como é o da dança.

Se por um lado existia a necessidade de clarificar, sob distintos pontos de vista, a

Comun. \& Inf., Goiânia, GO, v. 17, n. 2, p. 70-87, jul./dez. 2014 
entrevista a William Forsythe, com o propósito de aceder às questões estruturantes através de uma análise categorial, por outro lado tínhamos presente uma análise mais experiencial das correções realizadas num cartaz onde estava o seu ensaio. Este ensaio serviu como ponto de partida e propiciou as primeiras respostas às nossas inquietações.

Ao conjugar os quatro instrumentos, percebemos que características do "objeto coreográfico" existem nos dois discursos (WF e equipa), tornando-o num conceito de cariz material. As entrevistas, assim como os outros instrumentos metodológicos facilitaram-nos a compreensão do conceito assim como a sua aplicabilidade, transposição e transferibilidade para um espaço de instalação.

\section{AGRADECIMENTOS}

Ao Professor Doutor Daniel Tércio pela sua contribuição e linhas orientadoras na redação deste artigo. À Fundação para a Ciência e Tecnologia. Este trabalho foi financiado pelo Estado Português através da FCT - no âmbito da bolsa de doutoramento SFRH/BD/45054/2008 em Estudos Artísticos.

\section{REFERÊNCIAS}

DENZIN, K. The research act in sociology. Chicago: Aldine, 1970.

FONTE, Carla. Investigar narrativas e significados: a Grounded Analysis como metodologia de referência. Revista da Faculdade de Ciências Humanas e Sociais, Porto, v. [s.i.], n. 2, p. 290297, 2005.

FORSYTHE, W. Choreographic objects. In: BIRNBAUM, D.; FORSYTHE, W.; WEISBECK, M. Suspense. Alemanha, 2008.

GABLIK, S. The object lesson. In: Magritte, Londres: Thames and Hudson, 1970. p. 102-125.

MEDEIROS, Ana Margarida Marques de Macedo Guimarães. Análise do campo coreográfico contemporâneo: a coreografia enquanto proposta projectual de espaço. 2014. Tese (Doutorado) Curso de Motricidade Humana, Faculdade de Motricidade Humana, Universidade de Lisboa, Lisboa, 2014.

MEDEIROS, A.; TEIXEIRA, Z. Scattered crowd: perspectivas convergentes na análise de um objecto coreográfico. In: CONGRESSO IBERO-AMERICANO EM INVESTIGAÇÃO QUALITATIVA, 3., Badajoz. Anais... [s.n.], 2014. p. 246-251.

SEALE, Clive. Quality in Qualitative Research. Qualitative inquiry, London, v. 5, n. 4, p.465478, nov. 1999.

STRAUSS, A; CORBIN, J. Pesquisa qualitativa: técnicas e procedimentos para o desenvolvimento da teoria fundamentada. Porto Alegre: Artmed, 2008.

Recebido em: 28/09/2014

Aceito em: 30/09/2014

Publicado em: 10/12/2014

Comun. \& Inf., Goiânia, GO, v. 17, n. 2, p. 70-87, jul./dez. 2014 